\title{
Desafios no direcionamento e na priorização das intervenções das políticas de combate à pobreza nos municípios cearenses
}

\author{
Cláudio André Gondim Nogueira \\ Instituto de Pesquisa e Estratégia Econômica do Ceará (Ipece)
}

Sérgio Henrique Arruda Cavalcante Forte

Universidade de Fortaleza (Unifor)

Apesar dos avanços recentes, a pobreza ainda persiste no Ceará. Então, com base no "Triângulo Pobreza-Crescimento-Desigualdade" descrito por Bourguignon (2003, 2004), foram estimadas as elasticidades da pobreza em relação ao crescimento econômico e à desigualdade para identificar desafios na priorização das intervenções de combate à pobreza nos municípios cearenses. Os resultados mostram que os valores de ambas as sensibilidades estimadas são relativamente pequenos, indicando que as políticas têm potencialmente baixa capacidade de reduzir a pobreza. Argumenta-se, no entanto, que elas podem ser mais efetivas se forem consideradas as características particulares de cada município. Uma questão importante decorre da identificação de um grupo de municípios em que a sensibilidade das políticas é muito baixa, sendo que estes são os que, em geral, apresentam as piores situações relativas em termos da proporção de pobres e da desigualdade. Assim, se for privilegiada a efetividade potencial, as disparidades entre os municípios poderão aumentar.

Palavras-chave: políticas públicas, pobreza, administração municipal - Ceará

[Artigo recebido em 27 de julho de 2017. Aprovado em 21 de maio de 2018.] 


\section{Desafíos en el direccionamiento y en la priorización de las intervenciones de las políticas de combate a la pobreza en los municipios de Ceará}

A pesar de los avances recientes, la pobreza aún persiste en Ceará. Por lo tanto, con base en el "Triángulo Pobreza-Crecimiento-Desigualdad" descrito por Bourguignon (2003, 2004), fueron estimadas las elasticidades de la pobreza en relación al crecimiento económico y a la desigualdad para identificar desafíos en la priorización de las intervenciones de combate a la pobreza en los municipios de Ceará. Los resultados muestran que los valores de ambas sensibilidades estimadas son relativamente pequeños, indicando que las políticas tienen potencialmente baja capacidad para reducir la pobreza. Se argumenta, sin embargo, que pueden ser más efectivas si se consideran las características particulares de cada municipio. Una cuestión importante se deriva de la identificación de un grupo de municipios en los que la sensibilidad de las políticas es muy baja, siendo que estos son los que, en general, presentan las peores situaciones relativas en términos de la proporción de pobres y de la desigualdad. Así, si se privilegia la efectividad potencial, las disparidades entre los municipios pueden aumentar.

Palabras clave: políticas públicas, pobreza, administración municipal - Ceará

\section{Challenges in directing and prioritizing interventions in poverty reduction policies in the municipalities of Ceará}

Despite recent advances, poverty still persists in Ceara. Then, based on the "PovertyGrowth-Inequality Triangle" described by Bourguignon $(2003,2004)$, poverty elasticities in relation to economic growth and inequality were estimated in order to identify challenges in the prioritization of interventions to combat poverty in Ceara's municipalities. The results show that the values of both estimated elasticities are relatively small, indicating that policies have potentially low ability to reduce poverty. It is argued, however, that they can be more effective if one considers the particular characteristics of each municipality. An important issue arises from the identification of a group of municipalities where the sensitivity of policies is very low, which are usually the worst in terms of the proportion of poor and inequality. Thus, if potential effectiveness is privileged, disparities between municipalities may increase.

Keywords: public policies, poverty, municipal administration - Ceará 


\section{Introdução}

Em um contexto em que as informações são mais bem difundidas e que os cidadãos têm mais consciência de seus direitos e passam a cobrar por mais eficiência, eficácia e efetividade na execução das políticas públicas, os governos são pressionados a oferecer bens e serviços que realmente melhorem a qualidade de vida da população (ANDREWS, 2013; CATELLI; SANTOS, 2004; MACROPLAN, 2016; NogueirA; PONTES, 2013, 2015).

No caso do Ceará, um estado relativamente pobre, que, segundo dados recentes, responde por aproximadamente $4,5 \%$ da população brasileira e apenas 2,2\% da economia do país, a questão da pobreza ainda é fundamental (BARRETo et al., 2014). Apesar dos avanços registrados nos últimos anos, decorrentes (dentre outros fatores) das políticas públicas implementadas em todas as esferas de governo, a pobreza e uma significativa desigualdade de renda ainda persistem. Com isso, uma parte da população cearense ainda convive com a falta de acesso a bens e serviços que são essenciais a uma vida digna e à sua inclusão plena na sociedade. Mais especificamente, a análise dos dados disponíveis sugere que há um "núcleo duro" da pobreza que é menos sensível às políticas públicas que têm sido e implementadas, fazendo-se necessário um esforço de aperfeiçoamento das mesmas para que resultados mais expressivos e consistentes sejam alcançados (BARRETo et al., 2014; PNUd; IPEA; FJP, 2013).

Assim, como base para a análise dessa problemática, considerou-se o chamado "Triângulo Pobreza-Crescimento-Desigualdade", proposto por Bourguignon (2003, 2004, 2005) e que foi discutido e validado por outros autores tais como Assis, Medeiros e Nogueira (2017), Fosu (2009, 2011, 2015), Kalwij e Verschoor (2007), Kapoor (2013), Marinho e Araújo (2012), e Zaman e Khilji (2013), em que a redução da pobreza estaria diretamente ligada basicamente ao crescimento econômico e à melhoria da distribuição de renda e, assim, as políticas públicas devem ser desenhadas e implementadas dentro de uma estratégia de desenvolvimento no sentido de estimular esses efeitos.

Com base neste arcabouço, entende-se que é essencial para se elevar os níveis de efetividade das intervenções conhecer a sensibilidade da pobreza às estratégias que procuram estimular o crescimento da renda e a redução da desigualdade, a fim de se propor alguns direcionamentos para as políticas públicas de combate à pobreza no Estado, com destaque para o processo de priorização dos municípios cearenses para receber intervenções e recursos. No caso, devem ser privilegiados aqueles em pior situação relativa? Ou será que devem ser observadas as características locais que podem afetar a efetividade das intervenções efetuadas? Ou ainda, será que todos esses critérios poderiam ser considerados em conjunto? 
Então, com base nesses questionamentos, o presente artigo procura responder à seguinte questão de pesquisa: como as políticas públicas de combate à pobreza podem ser mais bem direcionadas ao serem levadas em conta as características dos municípios cearenses e a efetividade potencial das intervenções?

Portanto, o objetivo principal deste artigo é, por meio das referidas sensibilidades (elasticidades) calculadas a partir das estimativas de um modelo econométrico com dados em painel, considerar alguns desafios fundamentais na priorização das intervenções das políticas públicas de combate à pobreza nos municípios cearenses. Em específico, propõe-se um critério intuitivo em que os municípios em pior situação relativa (em termos da proporção de pobres e da desigualdade) teriam prioridade, testando-se por meio de uma análise de correspondência se o referido critério é compatível com a busca por maiores níveis de efetividade das políticas públicas, associada às elasticidades estimadas.

A relevância dessa pesquisa pode ser considerada sob várias perspectivas. Primeiramente, o estudo possui relevância empírica e contextual, uma vez que faz uma estimativa das referidas elasticidades para os municípios cearenses, considerando especificamente a linha de pobreza contemplada pelo Fundo Estadual de Combate à Pobreza (Fecop) do Governo do Estado do Ceará (HoLANDA; RosA, 2004a). O artigo também possui relevância prática, pois as estimativas e análises efetuadas se prestam a direcionar melhor as políticas de combate à pobreza no Ceará em uma perspectiva espacial. Possui ainda relevância metodológica, uma vez que se efetua uma análise inédita de correspondência entre grupos prédeterminados de municípios considerando, por um lado, as elasticidades e, por outro, a proporção de pobres e uma medida de desigualdade de renda. Além de maior rigor na análise dos dados, é possível argumentar que a utilização da referida técnica e os resultados obtidos permitem considerar questões teóricas importantes no âmbito do estudo das políticas públicas relacionadas à pobreza, relacionando as perspectivas da efetividade e da equidade, como será mais bem detalhado adiante.

\section{Referencial teórico}

Conforme foi sugerido na introdução, existem várias concepções acerca de como caracterizar um indivíduo como pobre. A literatura considera duas abordagens principais: uma ligada à ideia de que a pobreza caracteriza-se por uma privação acentuada de bem-estar e outra em que a pobreza pode ser entendida basicamente como a privação de renda, que não permitiria ao indivíduo ter o acesso adequado a bens e serviços que satisfazem as suas necessidades fundamentais (AzEVEDo; Burlandy, 2010; HolandA; RoSA, 2004a; RochA, 2006; SEN, 2000; THORBECKE, 2007). 
Nesse contexto, uma questão importante é que, quanto mais complexa e abrangente for a concepção de pobreza adotada, mais difícil tende a ser sua mensuração. Portanto, optou-se nesta pesquisa pela segunda abordagem. Dessa forma, é possível utilizar indicadores de renda monetária para identificar e medir a pobreza, e a questão fundamental seria, então, determinar um nível de renda abaixo do qual um indivíduo será considerado pobre, o que caracterizará a chamada linha de pobreza (HoffMAN, 2006; HolANDA; RosA, 2004a; NOgUeIRA, 2009; ROCHA, 2006; SACHS, 2005; THORBECKE, 2007).

Existem várias perspectivas para tanto. Rocha (2006), por exemplo, cita estudos nacionais e internacionais em que a linha de pobreza é calculada a partir das necessidades nutricionais mínimas dos indivíduos e do consumo não alimentar de itens essenciais ligados à habitação, vestuário, transporte, comunicação, saúde e cuidados pessoais etc. Já o Banco Mundial tem utilizado o critério de 1 ou 1,25 dólar PPC (por dia per capita) como o nível de renda mínimo para que uma família não seja classificada como abaixo da linha de pobreza. Ademais, em estudos nacionais também se utiliza como ponto de corte de pobreza a média mensal da renda domiciliar per capita, sendo considerados pobres aqueles com renda mensal inferior a $1 / 2$ salário mínimo. Finalmente, o Governo Federal brasileiro instituiu uma linha de pobreza de $\mathrm{R} \$ 140,00$ em 2009, depois corrigida para $\mathrm{R} \$ 154,00 \mathrm{em}$ junho de 2014 (AMATO, 2014; HolandA; RosA, 2004a; LouREIRO; SUliano, 2009; NOGUEIRA, 2009; PNUD, 2016).

Então, seja qual for o critério utilizado para se determinar a linha de pobreza, de maneira formal, conforme Bourguignon (2003) e Hoffman (2006), a proporção de pobres $(H)$, para uma população com $n$ indivíduos, seria dada por $H=k / n$, com $0 \leq \mathrm{H} \leq 1$, em que $\mathrm{k}$ representa o número de indivíduos com rendas menores ou iguais a z (linha de pobreza). Como é possível perceber, essa proporção é fortemente influenciada pelo valor de $z$, de tal forma que quanto maior ele for, mais pobres haverá em uma população.

Assim, seguindo o que foi proposto por Bourguignon (2003), se y representa o padrão de vida individual, pode-se representar a distribuição de renda no período $t$ pela função de distribuição cumulativa $F_{t}(Y)$, que fornece a proporção da população com padrão de vida, ou renda, $y<$ Y. Então, considerando a linha de pobreza definida acima, pode-se definir a proporção de pobres em t como:

$$
\mathrm{H}_{\mathrm{t}}=\mathrm{F}_{\mathrm{t}}(\mathrm{z})
$$

Então, a variação da pobreza entre dois pontos do tempo t e t' seria dada por:

$$
\begin{aligned}
& \Delta \mathrm{H}=\mathrm{H}_{\mathrm{t}^{\prime}}-\mathrm{H}_{\mathrm{t}}=\mathrm{F}_{\mathrm{t}^{\prime}}(\mathrm{z})-\mathrm{F}_{\mathrm{t}}(\mathrm{z}) . \\
& \mathrm{H}_{\mathrm{t}}=\mathrm{F}_{\mathrm{t}}(\mathrm{z}) \mathrm{H}_{\mathrm{t}}=\mathrm{F}_{\mathrm{t}}(\mathrm{z})
\end{aligned}
$$


Então, a variação da pobreza entre dois pontos do tempo t e t' seria dada por:

$\Delta \mathrm{H}=\mathrm{H}_{\mathrm{t}}{ }^{\prime}-\mathrm{H}_{\mathrm{t}}=\mathrm{F}_{\mathrm{t}^{\prime}}(\mathrm{z})-\mathrm{F}_{\mathrm{t}}(\mathrm{z})$

Bourguignon (2003, p. 8) argumenta que

Para mostrar a contribuição do crescimento na mudança na proporção de pobres, é conveniente definir a distribuição de renda relativa no período t como a distribuição de rendas após normalizá-las pela média da população. Isso é equivalente a definir a distribuição de renda de uma maneira que é independente das escalas de renda. Seja $\tilde{F}_{t}(X) \tilde{F}_{t}(X)$ essa distribuição. Com essa definição, qualquer variação na distribuição de renda poderá, então, ser decomposta em (a) uma variação proporcional em todas as rendas que deixam a distribuição de rendas relativas, $\tilde{F}_{t}(X)$ $\tilde{F}_{t}(X)$, inalterada; e (b) uma mudança na distribuição das rendas relativas que, por definição, é independente da média. Por razões óbvias, a primeira variação será chamada de "efeito crescimento" enquanto que a segunda será denominada de "efeito distributivo".

Essa decomposição, que já havia sido discutida por Datt e Ravallion (1992) e Kakwani (1993), pode ser verificada no Gráfico 1, que mostra a densidade da distribuição de renda (representada por uma escala logaritmíca no eixo horizontal), em que $\mathrm{F}($ ) representa a área sob as curvas de densidade. Dessa forma, se for a linha de pobreza arbitrariamente estabelecida, por exemplo, em $\$ 1,00$ por dia como no exemplo abaixo, a proporção de pobres seria dada pela área sob a curva de densidade à esquerda dessa linha (para outros valores de $z, o$ raciocínio seria similar).

O referido autor, ao ilustrar uma mudança da distribuição inicial para uma nova, introduz uma etapa intermediária, que é o deslocamento horizontal da densidade inicial para a curva (I). No caso, como a renda está em uma escala logarítmica, a mudança entre a distribuição inicial e (I) corresponderia ao "efeito crescimento", pois representa o mesmo aumento proporcional de todas as rendas na população. Já o movimento de (I) para a distribuição final permite a mensuração do chamado "efeito distributivo", uma vez que captaria a mudança na distribuição de rendas "relativas" dado que, neste caso, haveria uma média constante de renda (BOURGUIGNON, 2003). 
Gráfico 1 -Decomposição da mudança na distribuição e na pobreza a partir dos efeitos distributivo e de crescimento

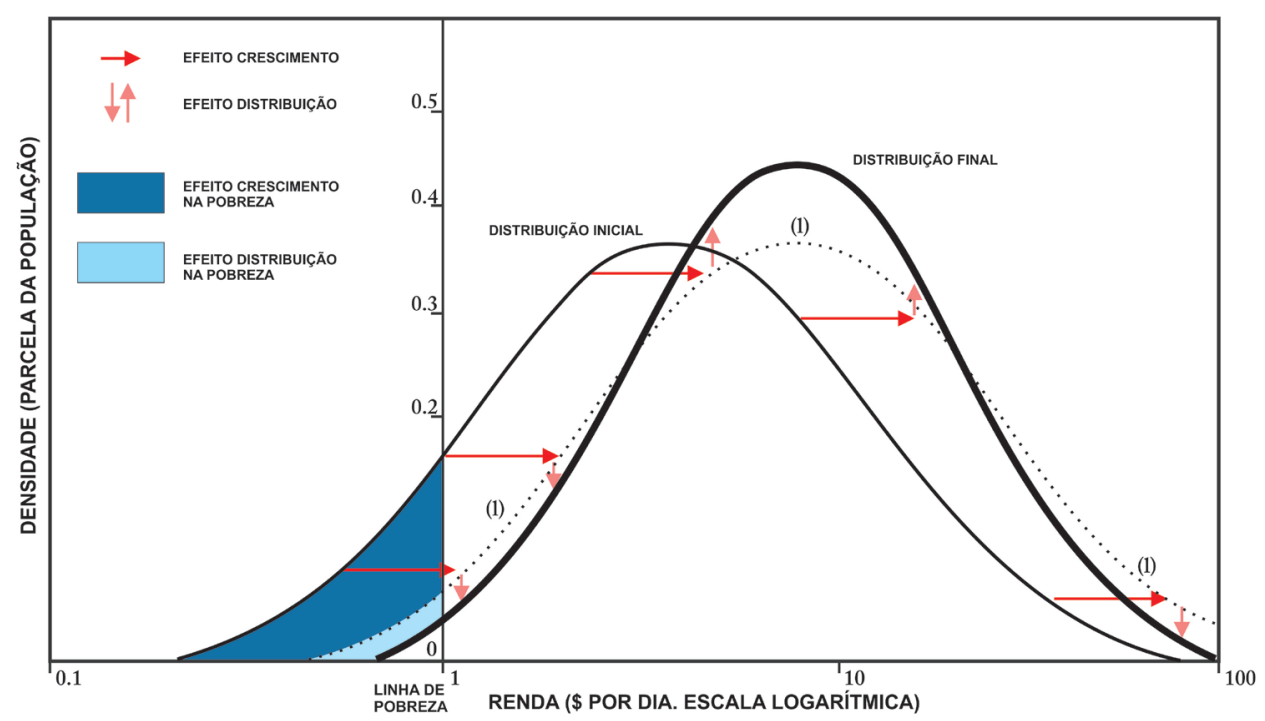

Fonte: Adaptado pelos autores (2017) a partir de Bourguignon (2003, p. 9).

Então, o movimento da distribuição inicial para a curva intermediária (I) e então para a nova distribuição, ilustrado no Gráfico 5, pode ser descrito como:

$$
\Delta \mathrm{H}=\mathrm{H}_{\mathrm{t}^{\prime}}-\mathrm{H}_{\mathrm{t}}=\left[\tilde{\mathrm{F}}_{\mathrm{t}}\left(\frac{z}{\bar{y}_{\mathrm{t}^{\prime}}}\right)-\tilde{\mathrm{F}}_{\mathrm{t}}\left(\frac{z}{\bar{y}_{\mathrm{t}}}\right)\right]+\left[\tilde{\mathrm{F}}_{\mathrm{t}^{\prime}}\left(\frac{\mathrm{z}}{\overline{\mathrm{y}}_{\mathrm{t}^{\prime}}}\right)-\tilde{\mathrm{F}}_{\mathrm{t}}\left(\frac{\mathrm{z}}{\overline{\mathrm{y}}_{\mathrm{t}^{\prime}}}\right)\right]
$$

Essa expressão, que é uma aplicação direta da fórmula geral proposta por Datt e Ravallion (1992) no caso da proporção de pobres, divide-se em duas partes em que a primeira corresponde ao efeito crescimento considerando uma distribuição de renda relativa "constante", $\tilde{\mathrm{F}}_{\mathrm{t}}\left(\mathrm{)} \tilde{\mathrm{F}}_{\mathrm{t}}(\mathrm{C})\right.$, o que corresponde à translação da curva de densidade ao longo do eixo horizontal, enquanto que a segunda parte formaliza o efeito distributivo (i.e., a variação na distribuição relativa da renda), $\tilde{\mathrm{F}}_{\mathrm{t}^{\prime}}(\mathrm{X})-\tilde{\mathrm{F}}_{\mathrm{t}}(\mathrm{X}) \tilde{\mathrm{F}}_{\mathrm{t}^{\prime}}(\mathrm{X})-\tilde{\mathrm{F}}_{\mathrm{t}}(\mathrm{X})$, ao novo nível da linha de pobreza "relativa", que é a razão entre a linha de pobreza absoluta e a renda média, $\mathrm{X}=\mathrm{z} / \overline{\mathrm{y}}_{\mathrm{t}}{ }^{\prime} \mathrm{X}=\mathrm{z} / \overline{\mathrm{y}}_{\mathrm{t}}^{\prime}$ (BOURGUIGNON, 2003).

Um aspecto importante associado a esse tipo de decomposição é que seria possível derivar elasticidades, que mensurariam a sensibilidade da pobreza aos efeitos decorrentes de variações na renda e na sua distribuição. Para tanto, deverse-ia especificar um modelo empírico para que essas elasticidades sejam estimadas adequadamente. Nesse sentido, Bourguignon (2003) propôs um modelo que virou referência na literatura e foi aplicado (ou adaptado) por vários autores (ASsIS; 
Medeiros; Nogueira, 2017; Fosu, 2009, 2011, 2015; KalWIJ; Verschoor, 2007; KAPOOR, 2013; MARINHO; ARAÚJO, 2012; ZAMAN; KHILI, 2013).

Nesse contexto, é importante ressaltar que a estimação dessas elasticidades é bastante relevante, pois elas mostram ao nível geográfico pertinente a sensibilidade da proporção de pobres a variações da renda (derivado do crescimento econômico) e da desigualdade, indicando que tipo de política, portanto, poderia ser mais efetiva para lidar com o problema da pobreza.

Essa estimação, portanto, está em consonância com os avanços que vêm ocorrendo no âmbito da gestão pública, uma vez que as modernas administrações não podem perder o foco nos resultados transformadores, aqueles que são alcançados em uma perspectiva de longo prazo, diretamente ligados à busca por maiores níveis de efetividade das políticas públicas (HoLANDA et al., 2006, 2008; Macroplan, 2016; Medeiros, 2010; Medeiros; Rosa; Nogueira, 2008; Nogueira; PONTES, 2013, 2015).

No caso específico do Ceará, pode-se considerar que desde 2003 o Estado vem buscando consolidar um modelo de gestão pública com forte ênfase na busca de resultados de longo prazo, tentando incorporar cada vez mais a participação popular e a integração das políticas públicas. Esse é um processo que tem sido irregular e marcado pela tentativa de enfrentar diversos obstáculos (HoLANDA et al., 2006, 2008; Macroplan, 2016; Medeiros, 2010; Medeiros; Rosa; Nogueira, 2008; NogueIRA; PONTES, 2013, 2015).

Apesar dos avanços verificados nos últimos anos, o plano de governo atual reconhece que ainda se fazem necessários grandes avanços na gestão pública do estado, tanto que o primeiro eixo governamental de articulação intersetorial é exatamente o que se refere à gestão democrática por resultados. No caso, buscar maiores níveis de eficiência, eficácia e, principalmente, de efetividade das políticas e das intervenções públicas é uma das principais prioridades nesse contexto (MACROPLAN, 2016).

Portanto, esse artigo procura contribuir no direcionamento das políticas públicas de combate à pobreza no Ceará e em seus municípios, o que se relaciona diretamente com esse esforço de aperfeiçoar a gestão pública e de se buscar maiores níveis de efetividade, visando melhorar a qualidade de vida da população cearense. 


\section{Metodologia}

\section{Base de dados}

A base de dados usada nesta pesquisa é proveniente do Atlas do Desenvolvimento Humano no Brasil (PNUD; IPEA; FJP, 2013). No caso, foram utilizados indicadores para os 184 municípios cearenses durante os anos de 1991, 2000 e 2010, quais sejam:

a. Proporção de pobres (PPOB): proporção dos indivíduos (que vivem em domicílios particulares permanentes) com renda domiciliar per capita igual ou inferior a $\mathrm{R} \$ 255,00$ mensais, em reais de agosto de 2010 , equivalente a $1 / 2$ salário mínimo nessa data. Vale salientar que essa especificação é compatível com a linha de pobreza utilizada pelo Fecop.

b. Renda per capita média (RDPC): razão entre o somatório da renda (em reais de agosto de 2010) de todos os indivíduos residentes em domicílios particulares permanentes e o número total desses indivíduos.

c. Índice de Gini (GINI): mede o grau de desigualdade existente na distribuição de indivíduos segundo a renda domiciliar per capita. Seu valor varia de 0 (quando não há desigualdade) a 1 (quando a desigualdade é máxima). 0 universo de indivíduos é limitado àqueles que vivem em domicílios particulares permanentes.

\section{Análise da pobreza no Ceará e em seus municípios}

Primeiramente, faz-se uma breve contextualização referente à evolução da pobreza no Ceará, considerando os anos em que os dados estão disponíveis, fazendo-se uma comparação do Ceará com o Brasil e, em seguida, uma análise da distribuição dos municípios cearenses. Efetua-se, também, uma análise de correlação entre PPOB e as demais variáveis consideradas no estudo: RDPC e GINI.

\section{Modelo econométrico e o cálculo das elasticidades}

A partir do trabalho de Bourguignon (2003), propõe-se um modelo validado em vários trabalhos (como foi mencionado anteriormente), que procura explicar a relação entre pobreza, crescimento e desigualdade nos municípios cearenses, qual seja:

$$
\begin{aligned}
& \Delta \ln P_{i t}=\beta_{1}+\beta_{2} \Delta \ln Y_{i t}+\beta_{3} \Delta \ln Y_{i t} G^{I}+\beta_{4} \Delta \ln Y_{i t}\left(\frac{z}{Y}\right)+\beta_{5} \Delta \ln G_{i t}+\beta_{6} \Delta \ln G_{i t} G^{I}+ \\
& \beta_{7} \Delta \ln G_{i t}\left(\frac{z}{Y}\right)+\alpha_{i}+\varepsilon_{i t}
\end{aligned}
$$

$$
\text { onde: } \mathrm{i}=1,2, \ldots, 184 \mathrm{i}=1,2, \ldots, 184 \text { e } \mathrm{t}=1991,2000,2010 \text {. }
$$


A variável dependente do modelo é a variação do logaritmo da proporção de pobres, $\left(\Delta \ln \mathrm{P}_{\mathrm{it}} \Delta \ln \mathrm{P}_{\mathrm{it}}\right.$ ), enquanto que as variáveis explicativas são a variação do logaritmo da renda média domiciliar per capita $\left(\Delta \ln \mathrm{Y}_{\mathrm{it}} \Delta \ln \mathrm{Y}_{\mathrm{it}}\right.$ ), a variação do logaritmo do coeficiente de $\mathrm{Gini}\left(\Delta \ln \mathrm{G}_{\mathrm{it}} \Delta \ln \mathrm{G}_{\mathrm{it}}\right)$, o índice de Gini do período inicial $\left(G^{I} G^{I}\right)$, e $\left(\frac{Z}{Y}\right)\left(\frac{Z}{Y}\right)$, que é a proporção da linha de pobreza $Z Z$ em relação à renda $Y Y$. Já os termos $\alpha_{i} \alpha_{i}$ dizem respeito à heterogeneidade não observada de cada município que não variam no tempo, i.e., podem ser entendidos como representantes de variáveis omitidas, que apesar de não observáveis, afetam a pobreza local. Esses efeitos podem ser tratados como fixos ou como resultados de um processo aleatório, e o teste de Hausman será utilizado para determinar qual tratamento é o adequado (LouREIRo; CoSTA, 2009). Por fim, o componente $\varepsilon_{\mathrm{it}} \varepsilon_{\mathrm{it}}$ é um termo aleatório com média zero e variância constante. Os subscritos ii e tt correspondem ao município e ao período de tempo da observação, respectivamente.

Assim, com base na equação (3), podem ser obtidas as elasticidades parciais renda-pobreza e desigualdade-pobreza ${ }^{1}$, respectivamente como:

$$
\begin{aligned}
& \mathrm{E}_{\mathrm{yp}}^{\mathrm{it}}=\frac{\partial \Delta \ln \mathrm{P}_{\mathrm{it}}}{\partial \Delta \ln \mathrm{Y}_{\mathrm{it}}}=\widehat{\beta}_{2}+\widehat{\beta}_{3} \mathrm{G}^{\mathrm{I}}+\widehat{\beta}_{4}\left(\frac{\mathrm{z}}{\mathrm{Y}}\right) \\
& \mathrm{E}_{\mathrm{gp}}^{\mathrm{it}}=\frac{\partial \Delta \ln \mathrm{P}_{\mathrm{it}}}{\partial \Delta \ln \mathrm{G}_{\mathrm{it}}}=\widehat{\beta}_{5}+\widehat{\beta}_{6} \mathrm{G}^{\mathrm{I}}+\widehat{\beta}_{7}\left(\frac{\mathrm{z}}{\mathrm{Y}}\right)
\end{aligned}
$$

$A$ equação (4) mostra a sensibilidade da pobreza com respeito à renda. Assim, o sinal de $\widehat{\beta}_{2} \widehat{\beta}_{2}$ deve ser negativo, pois um maior crescimento da renda deve, ceteris paribus, reduzir o crescimento da pobreza. Em contraste, espera-se que $\widehat{\beta}_{3} \widehat{\beta}_{3}$ seja positivo, pois um nível mais elevado de desigualdade inicial deve diminuir a taxa em que a aceleração do crescimento é transformada em redução da pobreza. $O$ sinal de $\widehat{\beta}_{4} \widehat{\beta}_{4}$ deve ser positivo, o que é consistente com a hipótese de que uma renda maior (em relação à linha de pobreza) geraria uma elasticidade de renda mais elevada. Já a equação (5) permite verificar a sensibilidade da pobreza com respeito à desigualdade. Dessa forma, o sinal de $\widehat{\beta}_{5} \widehat{\beta}_{5}$ é teoricamente positivo, pois se espera que para uma piora na distribuição de renda haja, ceteris paribus, um aumento da pobreza. Em contrapartida, conforme foi suposto por Bourguignon (2003), $\widehat{\beta}_{6} \widehat{\beta}_{6}$ e $\widehat{\beta}_{7} \widehat{\beta}_{7}$ deverão ser negativos, pois quanto maior for a desigualdade inicial ou a razão $Z / Y$ (i.e., quanto menor for a renda em relação à linha de pobreza

\footnotetext{
${ }^{1}$ Vale salientar que essas são elasticidades pontuais e específicas calculadas para os municípios cearenses. Os parâmetros estimados (betas) são constantes nas equações (4) e (5) de acordo com metodologia a ser utilizada (como será mais bem detalhado adiante), mas os valores pontuais das elasticidades serão potencialmente diferentes para cada localidade considerada devido aos valores de $\mathrm{G}^{\prime}, \mathrm{Z}$ e $\mathrm{Y}$ de cada uma delas.
} 
considerada), menor tenderá a ser a elasticidade desigualdade-pobreza (ASSIS; Medeiros; Nogueira, 2017; Bourguignon, 2003; Fosu, 2009, 2011, 2015; KALWIJ; VERSCHOOR, 2007; KAPOOR, 2013; MARINHO; ARAÚJO, 2012; ZAMAN; KHILI, 2013).

\section{Análise das elasticidades estimadas}

De posse das elasticidades renda-pobreza (apresentada em valores absolutos e denotada por ER_ABS) e desigualdade-pobreza (ED) para os municípios cearenses, primeiramente se realiza um estudo de suas distribuições considerando estatísticas descritivas básicas (BISQUERRA; SARRIERA; MARTINEZ, 2004). O objetivo é verificar, em uma perspectiva espacial, qual é a sensibilidade da pobreza em decorrência do crescimento econômico ou da mudança na distribuição de renda, o que pode ser fundamental para se determinar a efetividade das políticas implementadas.

Em seguida, com base nos valores das elasticidades e das suas respectivas médias, e considerando a correlação potencialmente positiva entre ER_ABS e ED, propõe-se a divisão dos municípios cearenses em quatro grupos distintos, quais sejam:

a. EL.1: ER_ABS Alta (maior ou igual à média) e ED Alta (maior ou igual à média);

b. EL.2: ER_ABS Alta (maior ou igual à média) e ED Baixa (menor que a média);

c. EL.3: ER_ABS Baixa (menor que a média) e ED Alta (maior ou igual à média);

d. EL.4: ER_ABS Baixa (menor que a média) e ED Baixa (menor que a média).

Vale salientar que esse é um tipo comum de caracterização de áreas geográficas que é bastante utilizada na literatura de desenvolvimento econômico (ANDREWS; HAY; MYERS, 2010; ASSIS; MedeIROS; NogUeIRA, 2017; RAY, 1998), e que será validada por meio de análise discriminante (PEREIRA, 2004) entre os grupos definidos e as mesmas variáveis utilizadas para delimitar os grupos. Ademais, esse é um tipo de análise que permite orientar de forma mais adequada que tipo de política deve ser preferencial em cada município cearense.

Finalmente, seguindo a ideia acima de classificação dos municípios em grupos, propõe-se um agrupamento similar considerando duas variáveis básicas do estudo que podem ser utilizadas para a priorização das intervenções das políticas públicas, PPOB e GINI, da seguinte maneira:

a. G.1: PPOB Alta (maior ou igual à média) e GINI Alto (maior ou igual à média);

b. G.2: PPOB Alta (maior ou igual à média) e GINI Baixo (menor que a média);

c. G.3: PPOB Baixa (menor que a média) e GINI Alto (maior ou igual à média);

d. G.4: PPOB Baixa (menor que a média) e GINI Baixo (menor que a média). 
A ideia, portanto, seria, por meio de uma análise de correspondência (CZermainski, 2004; Pestana; Gageiro, 2014), verificar se existe compatibilidade entre os grupos. Se houver, então, espera-se que as políticas tenham alto potencial de gerar positivos em termos de redução da proporção de pobres. Caso contrário, pode haver entraves importantes que comprometam a efetividade das mesmas.

\section{Resultados}

\section{A evolução da pobreza no Ceará e em seus municípios}

Conforme foi indicado anteriormente, optou-se neste estudo pela linha de pobreza compatível com a que é utilizada pelo Fundo Estadual de Combate à Pobreza (Fecop), em que o indivíduo é considerado pobre quando a sua renda domiciliar per capita for igual ou inferior a 1/2 salário mínimo (HOLANDA; ROSA, 2004a). Adotou-se este critério principalmente porque as orientações de política derivadas deste estudo se destinam aos gestores e tomadores de decisão relacionados ao referido fundo.

Assim, de forma a se ter uma ideia acerca do problema e a evolução da pobreza no Ceará, apresenta-se o Gráfico 2.

\section{Gráfico 2 - Proporção de pobres (PPOB): Ceará e Brasil - 1991, 2000 e 2010}

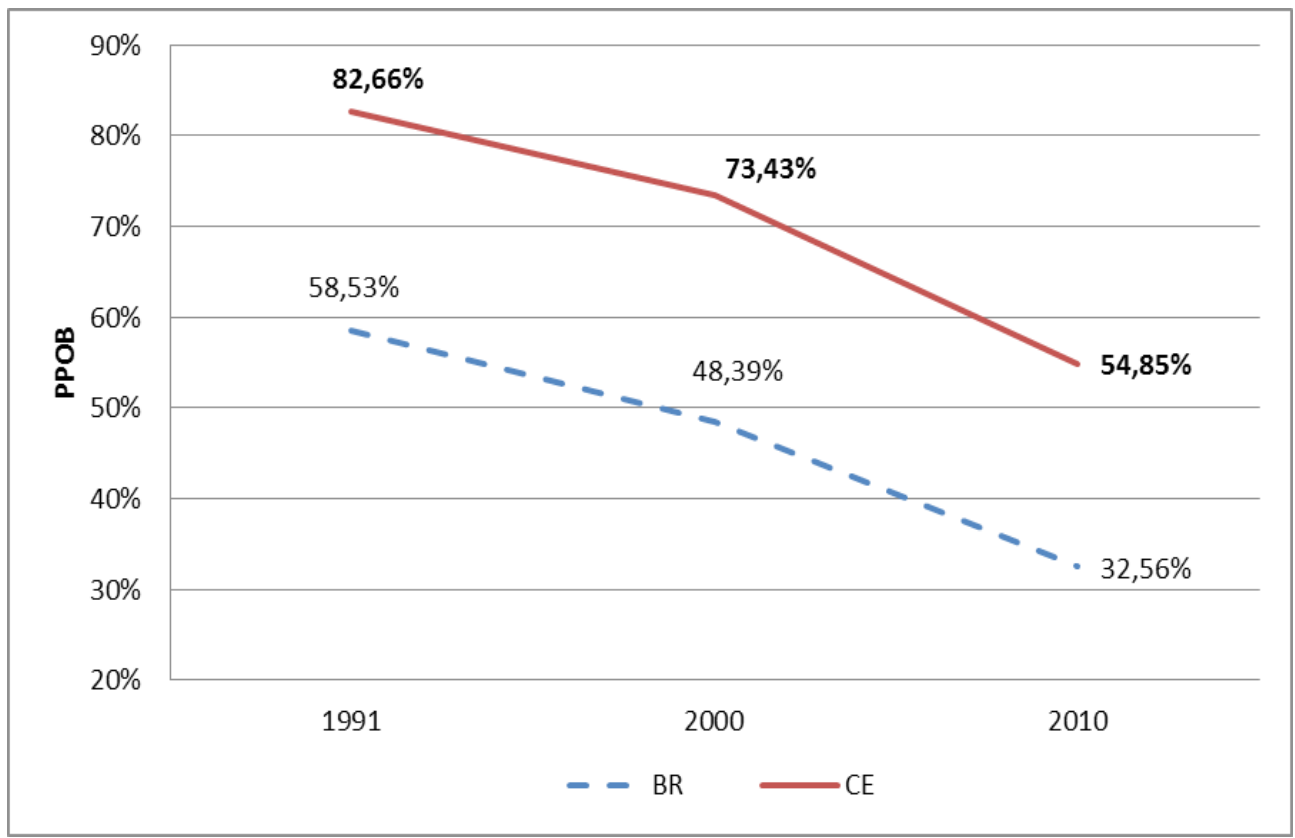

Fonte: Elaborado pelos autores (2017) com base em PNUD, IPEA e FJP (2013). 
Como é possível perceber, a proporção de pobres caiu consideravelmente ao longo do período em análise no Ceará, mas o estado ainda apresentava, em 2010, um percentual consideravelmente maior de pobres que o país. Conforme foi indicado antes, apesar de todas as transformações econômicas, sociais e institucionais experimentadas nos 20 anos em análise (PERO; CRUZ, 2015; RAMOS, 2015), detectase que uma parte significativa da população ainda está abaixo do nível de renda que Ihe garantiria níveis minimamente desejáveis de consumo de bens e serviços.

O Gráfico 3 apresenta as distribuições da proporção de pobres dos municípios cearenses. No caso, as referidas distribuições têm se deslocado para a esquerda ao longo do tempo, uma vez que a mediana diminuiu consistentemente; têm se tornado menos assimétricas à esquerda (embora Fortaleza, a capital do estado, possa ser considerada um outlier em todos os anos em análise); e apresentaram maiores amplitudes. Em outras palavras, de maneira geral, as proporções de pobres tenderam a ficar menores nos municípios cearenses, confirmando o que ocorreu com o Ceará, enquanto a distribuição delas tendeu a ficar menos concentrada nos valores mais elevados e, ao mesmo tempo, com uma maior dispersão, i.e., apresentando maiores discrepâncias entre os municípios nas melhores e nas piores condições.

Gráfico 3 - Distribuições de PPOB dos municípios cearenses: 1991, 2000 e 2010

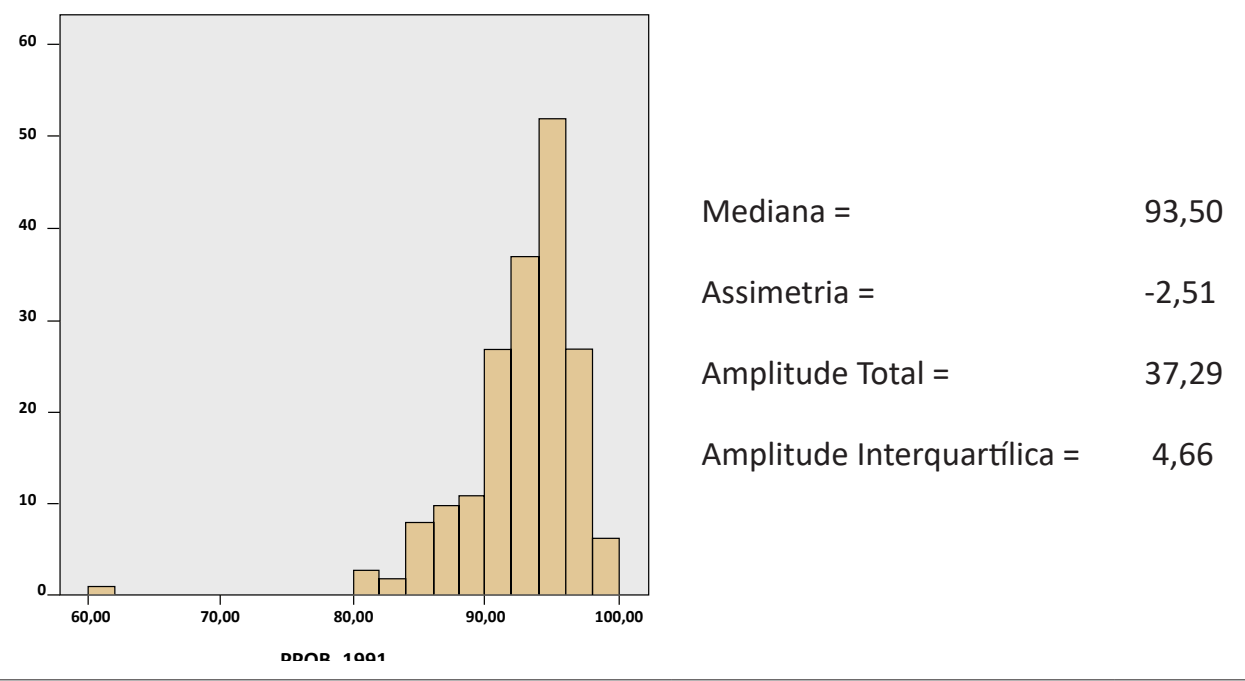



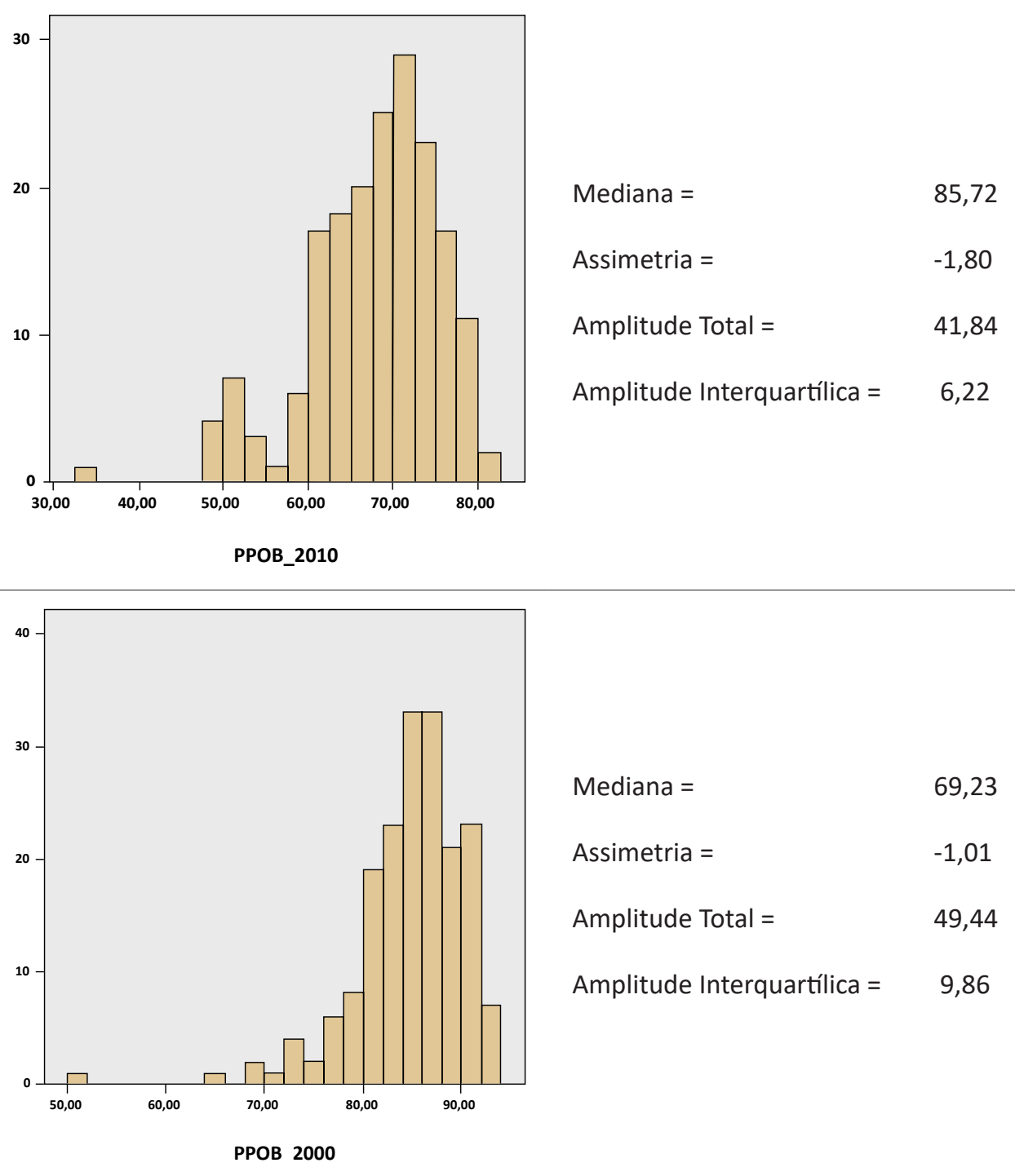

Fonte: Elaborado pelos autores (2017) com base em PNUD, IPEA e FJP (2013).

Outro aspecto relevante é que PPOB está significativamente correlacionada a outros indicadores, como se exemplifica no caso do Ceará, por meio da Tabela 1. Dessa forma, é possível constatar que, de maneira geral, a proporção de pobres é negativamente correlacionada com a renda per capita média (RDPC) e positivamente com o Índice de Gini (GINI), o que seria compatível com o que foi proposto por Bourguignon (2003, 2004, 2005). 
Tabela 1 -Correlações entre PPOB e RDPC e entre PPOB e GINI, calculadas a partir de dados municipais: Ceará - 1991, 2000 e 2010

\begin{tabular}{lccc}
\hline \multirow{2}{*}{ INDICADORES } & \multicolumn{3}{c}{ PPOB } \\
\cline { 2 - 4 } RDPC & $\mathbf{1 9 9 1}$ & $\mathbf{2 0 0 0}$ & $\mathbf{2 0 1 0}$ \\
\hline GINI & $-0,948^{* *}$ & $-0,925^{* *}$ & $-0,877^{* *}$ \\
\hline
\end{tabular}

Fonte: Elaborada pelos autores (2017) com base em PNUD, IPEA e FJP (2013).

Nota: * Significantes a $5 \%$. ${ }^{* *}$ Significantes a $1 \%$.

Vale salientar que as magnitudes das correlações de PPOB com RDPC são, em valores absolutos, muito maiores que as com GINI. Entretanto, isso não significa necessariamente que o crescimento econômico gera mais impactos sobre a redução da pobreza que a melhoria da distribuição de renda. No caso, a efetividade potencial das políticas de crescimento e de distribuição será mensurada por meio de elasticidades que, por sua vez, dependem de outros termos (como foi mostrado antes) e, dessa forma, dependendo de seus valores, pode haver uma inversão das prioridades.

\section{Estimativas do modelo econométrico}

Na Tabela 2, apresentam-se as estimativas do modelo econométrico proposto. No caso, o teste de Hausman indicou que o método mais adequado é o de efeitos fixos, uma vez que a hipótese nula do teste, de que o modelo deve ser estimado considerando efeitos aleatórios, foi rejeitada ao nível de $5 \%$ de significância.

Tabela 2 - Resultados das estimações por efeitos fixos para a pobreza

\begin{tabular}{lccc}
\hline \multirow{2}{*}{ Pobreza } & \multicolumn{3}{c}{ EFEITOS FIXOS } \\
\cline { 2 - 4 } & Coef. & $\mathbf{T}$ & $\mathbf{P}>\mathbf{t}$ \\
\hline Renda & $-1,010$ & $-7,00$ & 0,000 \\
\hline Renda*Gini $_{\text {t0 }}$ & 0,932 & 3,70 & 0,000 \\
\hline Renda*(Z/Y) $^{\prime}$ & 0,231 & 10,32 & 0,000 \\
\hline Gini & 1,293 & 7,37 & 0,000 \\
\hline Gini*Gini $_{\text {t0 }}$ & $-0,585$ & $-2,03$ & 0,044 \\
\hline Gini*(Z/Y) $_{\text {Constante }}$ & $-0,570$ & $-12,96$ & 0,000 \\
\hline $\mathrm{N}$ & $-0,033$ & $-3,87$ & 0,000 \\
\hline $\mathrm{R}^{2}:$ within & 368 & & \\
\hline Prob>F & 0,872 & & \\
\hline
\end{tabular}

Fonte: Elaborada pelos autores (2017) com base em PNUD, IPEA e FJP (2013). 
Por meio da Tabela 2, considerando a regressão com efeitos fixos, verifica-se que todos os coeficientes de inclinação parciais são significativos a $1 \%$, além de apresentarem sinais de acordo com o esperado. Com respeito às elasticidades, os coeficientes estimados permitem o seu cálculo que, como foi explicado, dependem tanto do nível de desigualdade no período inicial do município que está sendo considerado, como da relação entre a linha de pobreza e a renda média. Pode-se perceber isso pelos termos interativos que entraram na regressão para captar essa não linearidade do efeito da renda e da desigualdade sobre a pobreza.

\section{Estimativas e análise das elasticidades}

Com base nas estimativas do modelo proposto, foi possível calcular para todos os municípios cearenses, tendo como base o ano de 2010, a Elasticidade Renda da Pobreza e a Elasticidade Desigualdade da Pobreza conforme as expressões (4) e (5) apresentadas anteriormente. Em conformidade com Bourguignon (2003), todos os valores da Elasticidade Renda da Pobreza foram negativos, indicando que elevações na renda domiciliar per capita provocam reduções no percentual de pobres (diante disto, optou-se por apresentá-la em módulo). Por outro lado, todos os valores da Elasticidade Desigualdade da Pobreza foram positivos, denotando que reduções na desigualdade (medida pelo Índice de Gini) geram reduções na proporção de pobres.

O Gráfico 4 apresenta as distribuições dos valores das elasticidades estimadas. Como é possível perceber, todas as distribuições são razoavelmente simétricas, tendendo a maioria dos valores a se concentrar em torno das respectivas médias, sem a presença de valores extremos (i.e., em nenhum caso o escore $Z$ foi menor que -3 ou maior que 3 ).

Gráfico 4 - Histogramas das distribuições das elasticidades estimadas para os municípios cearenses: 2010
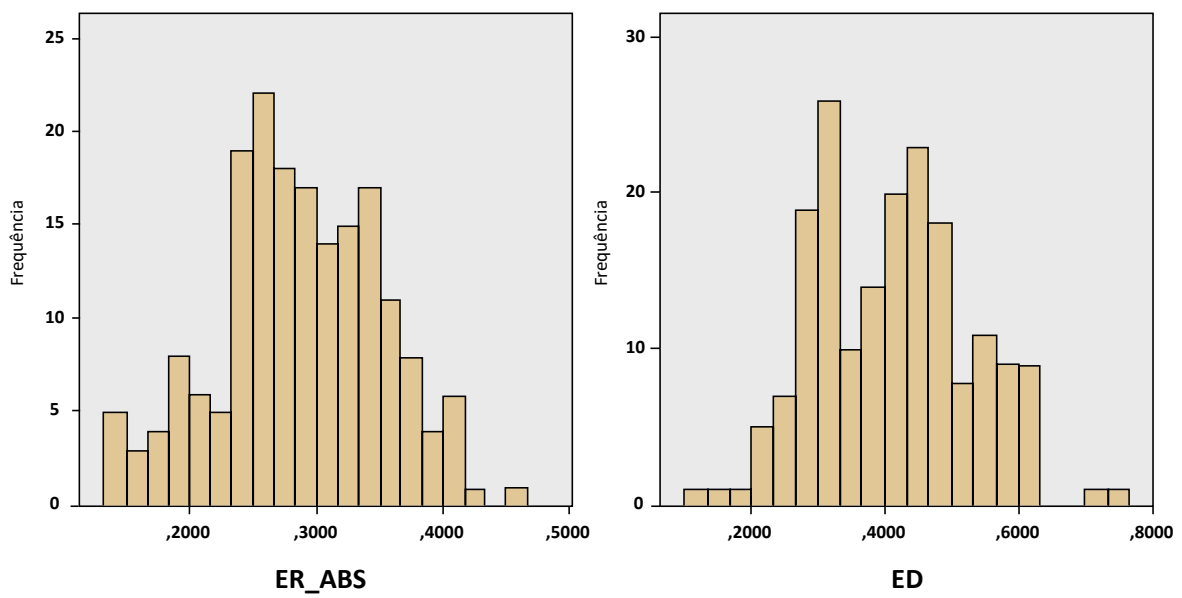

Fonte: Elaborado pelos autores (2017) com base em PNUD, IPEA e FJP (2013). 
As estatísticas básicas referentes a cada série são apresentadas na Tabela 3. Conforme ela ilustra, os valores das médias e das medianas são relativamente próximos entre si em cada distribuição e as dispersões dos valores dos municípios não foram extremamente elevadas, conforme indicam os coeficientes de variação. Assim, há diferenças entre os municípios em termos dos valores das elasticidades, mas essas diferenças não tenderam a ser extremamente altas. Adicionalmente, em todos os casos considerados não foram verificados coeficientes de assimetria e de curtose elevados, o que representa que elas podem ser consideradas, de maneira geral, como simétricas e mesocúrticas (similares ao que ocorre no caso da distribuição normal). Isso foi confirmado pelo teste de Shapiro-Wilk e parcialmente pelo de Kolmogorov-Smirnov (já que rejeitou a hipótese de normalidade no caso de ED).

Tabela 3 -Estatísticas descritivas referentes às elasticidades estimadas para municípios cearenses: 2010

\begin{tabular}{lcc}
\hline Estatística & ER_ABS & ED \\
\hline Mínimo & 0,1342 & 0,1179 \\
\hline Máximo & 0,4566 & 0,7465 \\
\hline Amplitude Total & 0,3224 & 0,6286 \\
\hline Média & 0,2877 & 0,4115 \\
\hline Mediana & 0,2865 & 0,4146 \\
\hline Desvio Padrão & 0,0650 & 0,1153 \\
\hline Coeficiente de Variação & 0,2260 & 0,2803 \\
\hline Assimetria & $-0,119$ & 0,206 \\
\hline Curtose & $-0,246$ & $-0,325$ \\
\hline Kolmogorov-Smirnov & 0,058 & $0,077^{* *}$ \\
\hline Shapiro-Wilk & 0,992 & 0,988 \\
\hline
\end{tabular}

Fonte: Elaborada pelos autores (2017) com base em PNUD, IPEA e FJP (2013).

Nota: ** Significante a $1 \%$. 
A partir dessa análise sucinta, é possível concluir que os valores estimados para as referidas elasticidades foram, em geral, muito baixos na avaliação para 2010. Para efeito de ilustração, considerando que os valores dessas elasticidades não tendem a variar bastante em um curto período de tempo, pode-se dizer que uma elevação de $1 \%$ no nível da renda per capita média (RDPC) em determinado município tende a gerar uma redução entre 0,1342\% e 0,4566\% em PPOB (lembrando que a Elasticidade Renda da Pobreza foi apresentada em módulo). Ademais, uma redução de $1 \%$ em GINI de um município poderia gerar uma redução em PPOB entre 0,1179\% e 0,7465\% (considerando os valores mínimo e máximo calculados).

As elasticidades estimadas também se mostraram significativamente correlacionadas entre si, como um coeficiente (em módulo) igual a 0,731, significante ao nível de $1 \%$, indicando que os municípios que apresentaram valores (absolutos) mais elevados da elasticidade renda tenderam a apresentar valores mais elevados das elasticidades de desigualdade.

A partir dessa constatação, faz sentido considerar a separação dos municípios cearenses, delineada anteriormente, em quatro grupos distintos de acordo com os valores das elasticidades estimadas. Para validar essa divisão, foi efetuada uma análise discriminante em que se verificou que ambas as elasticidades apresentaram significativo poder discriminante, e o modelo conseguiu prever corretamente o posicionamento de $94,0 \%$ dos municípios.

A dispersão dos dados e os agrupamentos (EL.1 a EL.4) são ilustrados com a ajuda do Gráfico 5. No caso, tem-se que EL.1 concentra os 74 municípios que apresentam as melhores respostas para as políticas que estimulam o crescimento econômico (e consequentemente a renda domiciliar per capita) e que reduzem a concentração da renda. Já os 75 municípios que compõem EL.4 seriam aqueles que apresentam respostas relativamente mais baixas para ambas as políticas. Os outros dois grupos, por sua vez, apresentam municípios com respostas mais relevantes para um tipo de política (crescimento econômico no caso de EL.2, com 15 municípios, e de distribuição de renda para EL.3, com 20 municípios). 
Gráfico 5 -Diagrama de dispersão e divisão por grupos dos municípios cearenses, conforme os valores das elasticidades estimadas: 2010

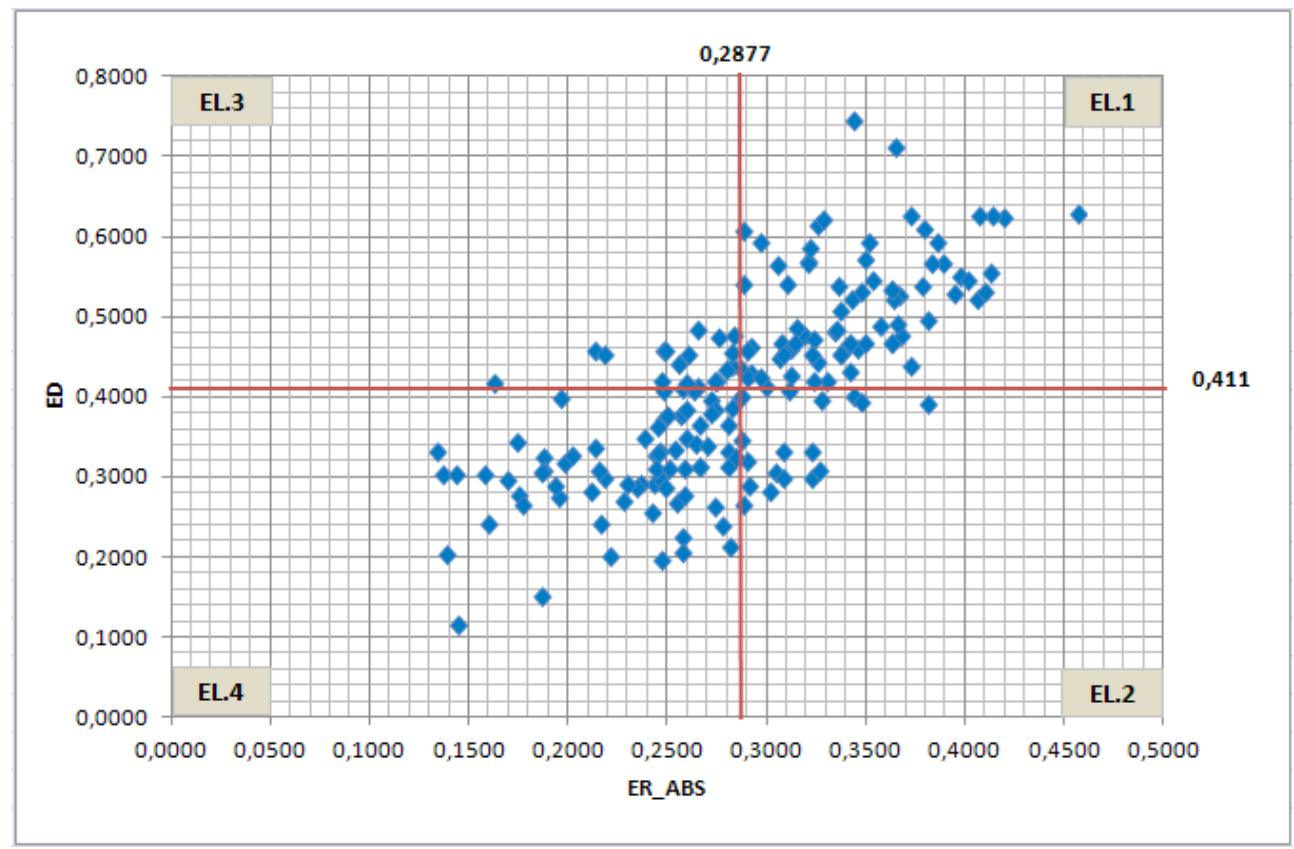

Fonte: Elaborado pelos autores (2017) com base em PNUD, IPEA e FJP (2013).

Assim, tomando-se o grupo EL.4 como exemplo, tem-se que ele agrega os municípios em que as intervenções têm que ser mais bem delineadas, pois, para uma dada variação na renda per capita média, esses municípios tenderiam a obter piores respostas em termos de redução da pobreza que os grupos EL.1 e EL.2, que apresentaram valores acima da média para a elasticidade renda. Similarmente, para uma dada redução no Índice de Gini, o que representa uma queda na desigualdade, esses municípios tenderiam a reduzir a sua proporção de pobres de forma menos intensa que aqueles que compõem El.1 e EL.3, que possuem elasticidades de distribuição mais elevadas.

Como se verificou também uma correlação positiva entre PPOB e GINI, os municípios foram agrupados de maneira semelhante à anterior, formando os grupos G.1 a G.4, em que o primeiro apresenta os maiores valores de ambas as variáveis e o G.4 os menores.

A Tabela 4 exibe a tabulação cruzada entre os grupos propostos. Então, por exemplo, considerando os municípios com as maiores elasticidades (EL.1), 15 estavam simultaneamente entre aqueles com as maiores proporções de pobres e desigualdades; quatro com aqueles com as maiores proporções de pobres, mas com baixa desigualdade; 18 com os relativamente mais desiguais, mas com as 
menores proporções de pobres; e, 37 com as menores desigualdades e com menor percentual de pobres (ver, também, a Figura 1).

Tabela 4 -Tabulação cruzada entre grupos classificados segundo ER_ABS e ED (EL.1 a EL.4) e PPOB e GINI (G.1 a G.4): 2010

\begin{tabular}{|c|c|c|c|c|c|c|}
\hline & & \multicolumn{4}{|c|}{ Grupos segundo os Indicadores } & \multirow{2}{*}{ Total } \\
\hline & & G.1 & G.2 & G.3 & G.4 & \\
\hline \multirow{4}{*}{$\begin{array}{l}\text { Grupos segundo } \\
\text { as Elasticidades }\end{array}$} & EL.1 & 15 & 4 & 18 & 37 & 74 \\
\hline & EL.2 & 11 & 4 & 0 & 0 & 15 \\
\hline & EL.3 & 3 & 1 & 8 & 8 & 20 \\
\hline & EL.4 & 43 & 23 & 1 & 8 & 75 \\
\hline Total & & 72 & 32 & 27 & 53 & 184 \\
\hline
\end{tabular}

Fonte: Elaborada pelos autores (2017) com base em PNUD, IPEA e FJP (2013).

O teste qui-quadrado de independência aplicado à Tabela 4 obteve uma estatística igual a 86,793, significante a 1\%, rejeitando, portanto, a hipótese de independência entre os grupos, ou seja, existe relação entre pelo menos alguns deles. Partindo desse resultado, apresentado na Tabela 5, a análise de correspondência entre os grupos em análise gerou três dimensões de análise $[\min (4,4)-1]$. Formalmente, como as duas primeiras dimensões explicam mais de $90 \%$, a terceira dimensão poderia ser descartada. Ademais, como a dimensão 1 possui inércia de 0,451 de um total de 0,472, i.e., 95,6\% do total, a separação entre os municípios deveria ser efetuada basicamente conforme as diferenças dos escores normalizados da primeira dimensão (CZERMAINSKI, 2004; PESTANA; GAGEIRO, 2014). 
Figura 1 - Mapas dos grupos de municípios cearenses conforme as elasticidades e os indicadores selecionados: 2010
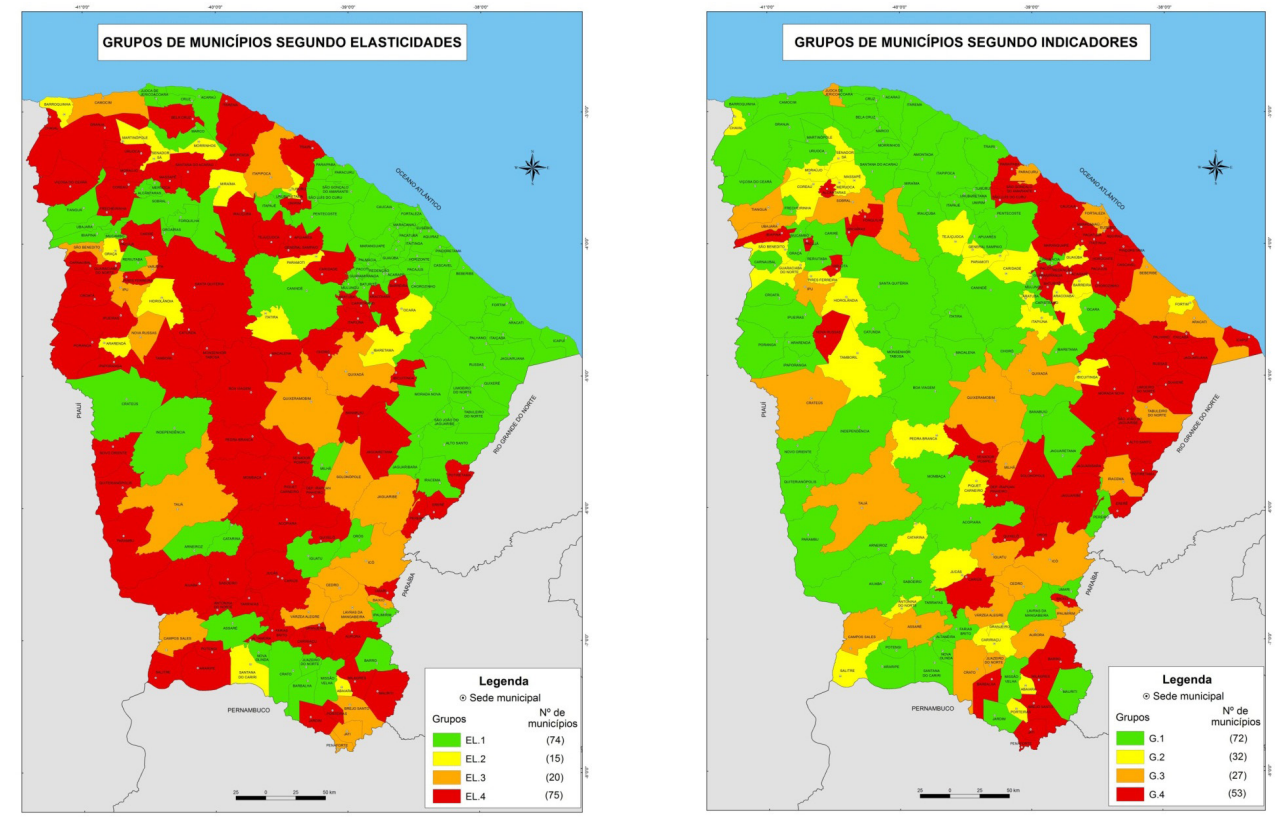

Fonte: Elaborada pelos autores (2017).

Tabela 5 -Sumário da análise de correspondência entre grupos classificados segundo ER_ABS e ED (EL.1 a EL.4) e PPOB e GINI (G.1 a G.4): 2010

\begin{tabular}{ccccccc}
\hline Dimensão & $\begin{array}{c}\text { Valor } \\
\text { Singular }\end{array}$ & Inércia & $\begin{array}{c}\text { Qui- } \\
\text { Quadrado }\end{array}$ & Sig. & \multicolumn{2}{c}{$\begin{array}{c}\text { Proporção de Inércia } \\
\text { Contabilizada }\end{array}$} \\
\hline 1 & 0,672 & 0,451 & - & - & 0,956 & Acumulada \\
\hline 2 & 0,128 & 0,016 & - & - & 0,035 & 0,991 \\
\hline 3 & 0,065 & 0,004 & - & - & 0,009 & 1,000 \\
\hline Total & - & $\mathbf{0 , 4 7 2}$ & $\mathbf{8 6 , 7 9 3}$ & $\mathbf{0 , 0 0 0 ^ { a }}$ & $\mathbf{1 , 0 0 0}$ & $\mathbf{1 , 0 0 0}$ \\
\hline
\end{tabular}

Fonte: Elaborada pelos autores (2017) com base em PNUD, IPEA e FJP (2013).

Nota: 9 graus de liberdade.

A representação gráfica dessa análise é feita por meio do Gráfico 6. Em ambos os Gráficos apresentam-se dois grandes agrupamentos razoavelmente semelhantes. Em termos das elasticidades, o primeiro congrega os grupos com as maiores elasticidades desigualdade da pobreza (EL.1 e EL.3), enquanto que o segundo apresenta aqueles com as menores (EL.2 e EL.4). 
Gráfico 6 -Representação gráfica da análise de correspondência entre grupos classificados segundo ER_ABS e ED (EL1 a EL4) e PPOB e GINI (G1 a G4): 2010
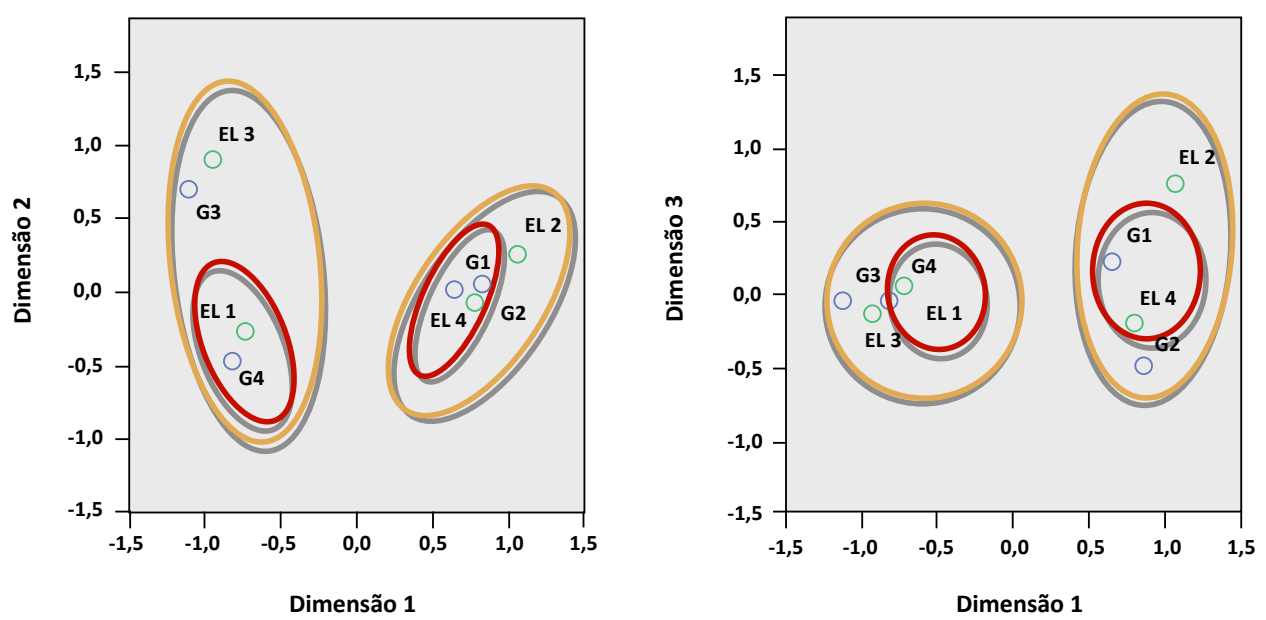

Fonte: Elaborado pelos autores (2017) com base em PNUD, IPEA e FJP (2013).

Ademais, verifica-se a proximidade entre os grupos EL.2 e G.2, e entre EL.3 e G.3. Por outro lado, verificou-se também uma grande proximidade entre EL.1 e G.4 e, também, entre EL4 e G1, o que pode ter implicações importantes sobre o direcionamento das políticas públicas de combate à pobreza no Ceará, como será discutido adiante.

\section{Discussão}

As estimativas e resultados apresentados na seção anterior permitiram a obtenção de três resultados principais:

1. a resposta em termos de uma redução da proporção de pobres nos municípios cearenses é menos que proporcional a um aumento em RDPC ou a uma redução em GINI considerando a linha de pobreza utilizada;

2. os municípios cearenses podem ser agrupados de tal forma que há um grupo (EL4) formado por nada menos que de 75 dos 184 municípios que apresentam tanto ER_ABS como ED abaixo de suas respectivas médias, i.e., esses seriam localidades em que tanto elevações de RDPC ou reduções em GINI tenderiam a gerar reduções baixas em PPOB;

3. em uma análise de correspondência, verificou-se que o grupo que possui os maiores valores para ER_ABS e ED apresenta-se bem próximo daquele que agrega os municípios com os menores níveis relativos de PPOB e GINI, i.e., aqueles que apresentam proporcionalmente menos pobres na população e 
menores níveis de desigualdade. Por outro lado, aqueles com as menores elasticidades estão próximos dos municípios proporcionalmente com mais pobres e mais desiguais.

Então, o que representariam na prática essas conclusões? Como elas podem ser utilizadas no melhor direcionamento do combate à pobreza no Ceará?

Com relação ao primeiro resultado, é importante considerar que os valores encontrados para os municípios cearenses são consideravelmente mais baixos que os encontrados em outros estudos que usam diferentes linhas de pobreza. No caso, como a usada neste trabalho é menos restritiva, i.e., uma vez que a metade de um salário mínimo no Brasil vale bem mais que o equivalente a US\$ 1,25 por dia, a proporção de pobres tende a ser menos sensível ao crescimento da renda ou a melhorias na sua distribuição. Em outras palavras, os aumentos da renda e/ ou a redução da desigualdade decorrentes das políticas públicas implementadas deveriam ser bem mais relevantes para que um indivíduo considerado pobre deixe de sê-lo (Assis; Medeiros; Nogueira, 2017; Bourguignon, 2003; Fosu, 2009, 2011, 2015; KALWIJ; VERSCHOOR, 2007; KAPOOR, 2013; MARINHO; ARAúJO, 2012; ZAMAN; KHILJI, 2013).

De forma a ilustrar esse argumento, considera-se, por exemplo, o trabalho de Assis, Medeiros e Nogueira (2017), que estimaram as mesmas elasticidades utilizando a linha da extrema pobreza (equivalente a $\mathrm{R} \$ 70$ em agosto de 2010). No caso, com essa outra linha, o módulo da Elasticidade Renda da Pobreza situouse entre 0,5461 e 1,2280, enquanto que a Elasticidade Desigualdade da Pobreza apresentou valores no intervalo de 0,6034 a 2,2397, ou seja, os seus valores foram bem mais elevados que os encontrados no presente estudo.

A principal implicação desse resultado é que, com uma linha de pobreza muito ampla, que expande consideravelmente o número de potenciais beneficiários, a focalização das políticas fica mais difícil (NERI, 2006). No caso do Ceará, por exemplo, com mais de $50 \%$ da população considerada pobre em 2010 , tornase bastante desafiador, no âmbito das políticas de crescimento e distributivas, desenhar iniciativas eficazes que combatam, de fato, a pobreza. Em um contexto como esse, deve-se ter o cuidado especial para se evitar a pulverização dos recursos e a implantação de alternativas genéricas que desconsideram as características específicas dos municípios (OliveIRA; Miro; BARRETo, 2013).

No caso do segundo resultado, a análise espacial relacionada ao bem-estar social e às condições de pobreza de uma região permite averiguar se existe um padrão na sua distribuição ou se ela se dissemina aleatoriamente no espaço geográfico. Para Chiarini (2008), a análise espacial é importante não somente para identificar onde a população pobre se localiza, mas principalmente por servir como instrumento 
capaz de capturar a heterogeneidade dentro de uma determinada região. Para o autor, a avaliação de indicadores agregados em nível global (país, estado) pode dar a (falsa) impressão de que as condições internas estão uniformemente distribuídas e, frequentemente, podem camuflar variações consideráveis em nível menor de desagregação territorial. Seguindo esta linha, Medeiros e Pinho Neto (2012) enfatizam a necessidade de se mapear o fenômeno da pobreza no Ceará para que se possa propor estratégias de desenvolvimento mais efetivas e ações públicas focadas, localizando-se territorialmente onde está a população pobre dos municípios cearenses.

Desta forma, o agrupamento proposto para os municípios com base nas elasticidades estimadas pode dar um relevante insight para direcionar as intervenções no âmbito de cada tipo de política quando se busca uma maior efetividade das mesmas. Provê, também, uma solução prática para a questão levantada por Bourguignon (2004), se as políticas de crescimento e de distribuição devem ser independentes ou fortemente inter-relacionadas.

Neste ponto, uma observação importante se faz necessária. É preciso considerar que os municípios também podem ser bastante heterogêneos. Sendo assim, pode haver, por exemplo, diferenças consideráveis em termos do tamanho da população e do número de pobres. Então, por exemplo, um município grande pode ter uma pequena proporção de pobres, mas o número absoluto de pessoas vulneráveis à pobreza pode ser elevado. Nos municípios pequenos, o inverso pode ocorrer. Logo, deve-se ter em mente essas diferenças quando forem comparadas as elasticidades e, principalmente, quando as intervenções forem implementadas.

Mais especificamente, conhecendo-se as características e particularidades de cada local seria a priori possível atacar com mais propriedade e de forma mais direcionada os problemas vividos por cada comunidade, escolhendo as alternativas com maior potencial de gerar os resultados esperados. Isso envolve, certamente, um relevante esforço para aprimorar a gestão dos programas e projetos, assim como uma capacidade de adequação de suas iniciativas às realidades encontradas. Abrange também avanços institucionais importantes para compatibilizar as políticas estaduais (e federais) com as municipais, proporcionando os incentivos adequados para que o combate à pobreza seja mais bem coordenado nas diversas esferas da gestão pública (ANDREWS, 2013; BARRETo et al., 2014; HolANDA et al., 2006; Holanda; Rosa, 2004b; Medeiros; Pinho Neto, 2012; OCDE, 2016; Oliveira; MIRO; BARRETO, 2013).

Os desafios listados acima não são triviais, principalmente quando se identifica que ao se priorizar os municípios em pior situação relativa, o que é compatível com o critério de equidade, essas localidades podem ser as que também apresentam o 
menor potencial de redução da pobreza em decorrência das políticas implantadas. No caso, essa é uma contribuição original deste artigo, sugerindo que haveria no contexto do Ceará, um trade-off entre efetividade e equidade nas políticas de combate à pobreza. Assim, haveria um dilema importante que os gestores e tomadores de decisão devem enfrentar, pois, se enfatizarem as intervenções nos municípios que mais precisam, a efetividade das mesmas pode ser reduzida, ao passo que, se centrar as ações nas áreas onde as políticas são potencialmente mais efetivas, há uma grande possibilidade de que as disparidades entre as localidades venham a se acentuar ao longo do tempo.

Isso vem a reforçar a argumentação aqui apresentada, de que as intervenções não podem ser genéricas, além de que não podem prescindir de um sistema que as monitore e avalie adequadamente, para que correções de rumo e redirecionamentos sejam efetuadas quando necessárias. Ademais, o conhecimento das necessidades das comunidades carentes deve ser priorizado, bem como o processo de seleção e aprovação das iniciativas e de alocação de recursos deve ser clara e objetivamente adequado para permitir que essas necessidades sejam atacadas da melhor maneira possível (BARReto et al., 2014; MACroplan, 2016; Medeiros; PinHo Neto, 2012; OCDE, 2016; Oliveira; MiRo; BARRETo, 2013).

\section{Conclusão}

Os resultados apresentados neste trabalho mostram que os tomadores de decisão e gestores possuem alguns desafios importantes na priorização das intervenções no combate à pobreza. No caso, diante do potencial relativamente baixo de resposta das políticas, torna-se importante que as particularidades e potencialidades de cada município sejam consideradas em busca de mais efetividade.

Com essa percepção, é bem possível que as estratégias tenham que ser repensadas, devendo ser descartadas as iniciativas genéricas que não consideram plenamente as realidades locais. Isso requer, portanto, um esforço no sentido de conhecer melhor quais são as verdadeiras necessidades e anseios da populaçãoalvo de cada área geográfica, de forma que as intervenções possam, de fato, transformar a realidade das pessoas mais carentes.

Entretanto, um grande dilema emerge quando as localidades que mais precisam das ações públicas para superar as deficiências existentes são exatamente aquelas que apresentam a menor perspectiva de sucesso. Assim, além da escolha de que áreas devem ser enfatizadas, o esforço de priorização deve ser feito também para selecionar adequadamente as estratégias e iniciativas a serem implementadas indicando, conforme Andrews (2013), que tipos de intervenções ou mudanças 
devem ser implantadas; quem deverá conduzi-las; quando elas deverão ocorrer e por quê; e como elas podem gerar resultados sustentáveis em longo prazo.

Nesse contexto, vale salientar que as atividades de monitoramento e avaliação são fundamentais, pois por meio delas é possível alocar melhor os recursos disponíveis, lidar com problemas de execução, e buscar o desejado aumento de efetividade das intervenções. E, com o desenvolvimento de uma cultura de avaliação, torna-se mais adequada a disseminação de melhores práticas (BARRETo et al., 2014; CHIARINI, 2008; Holanda; Rosa, 2004b; Oliveira; Miro; BarReto, 2013).

Como limitações do artigo tem-se, primeiramente, a base de dados que só está disponível até o ano de 2010 , pois não há dados municipais mais recentes para as variáveis consideradas. Adicionalmente, do ponto de vista metodológico, na estimação do modelo não foram relevados os potenciais efeitos espaciais entre municípios, não se avaliou a possibilidade de que os coeficientes estimados não sejam os mesmos para todos os municípios ou para grupos de municípios, nem foram consideradas as implicações decorrentes da adoção de outra linha de pobreza, como a que foi utilizada, por exemplo, por Assis, Medeiros e Nogueira (2017), que gera elasticidades com magnitudes mais elevadas em relação à linha contemplada no presente estudo. Finalmente, foram apresentadas de forma sintética as principais consequências estratégicas e gerenciais decorrentes dos resultados das análises efetuadas.

Assim, na perspectiva do desenvolvimento de estudos futuros, propõe-se o uso de outras metodologias para lidar com eventuais problemas técnicos não considerados. Mais importantemente, sugere-se o aprofundamento da discussão acerca da priorização e escolha de intervenções e da alocação de recursos no âmbito de uma política de combate à pobreza no Ceará abordando, com maior riqueza de detalhes, aspectos relacionados ao desenho e à implementação de políticas considerando as particularidades de cada local assim como as características e o potencial de cada tipo de iniciativa no âmbito das políticas de crescimento econômico e de distribuição de renda.

\section{Referências bibliográficas}

АмATO, F. Número de pobres no Brasil pode estar subestimado, aponta TCU. G1, 10 set. 2014. Disponível em: http://g1.globo.com/politica/noticia/2014/09/numerode-pobres-no-brasil-pode-estar-subestimado-aponta-tcu.html Consulta em: 15 mar. 2015.

ANDREWS, M. How do governments get great? Cambridge (MA): Harvard / John F. Kennedy School of Government, 2013 (Faculty Research Working Paper RWP13020). 
ANDREWS, M.; HAY, R.; MYERS, J. Governance indicators can make sense: under-five mortality rates are an example. Cambridge (MA): Harvard / John F. Kennedy School of Government, 2010 (Faculty Research Working Paper RWP10-015).

Assis, D. N. C.; Medeiros, C. N.; Nogueira, C. A. G. Extrema pobreza infantil, crescimento e distribuição de renda. Planejamento e Políticas Públicas, n. 48, p. 175-210, jan./jun. 2017.

Azevedo, D. C.; Burlandy, L. Política de combate à pobreza no Brasil, concepções e estratégias. Rev. Katál. Florianópolis, v. 13, n. 2, p. 201-209, jul./dez. 2010.

BARReto, F. A. et al. Comentários gerais e estratégias para o desenvolvimento social do Ceará. In: Barreto, F. A. F. D.; Menezes, A. S. B. (Orgs.) Desenvolvimento econômico do Ceará: evidências recentes e reflexões. Fortaleza: Ipece, 2014. p. 392402.

Bisquerra, R.; SARrierA, J. C.; MARTInez, F. Introdução à Estatística: enfoque informático com o pacote estatístico SPSS. Porto Alegre: Artmed, 2004. 255 p.

BOURGUIGNON, F. The growth elasticity of poverty reduction: explaining heterogeneity across countries and time periods. In: EICHER, T.; TURNOVSKY, S. (Eds.) Inequality and growth: theory and policy implications. Cambridge: The MIT Press, 2003. p. 3-26.

2004.

. The poverty-growth-inequality triangle. Washington, DC: The World Bank,

.The poverty-growth-inequality triangle: with some reflections on Egypt. Cairo: ECES, 2005. (Distinguished Lecture Series n. 22).

CATELLI, A.; SANTOS, E. S. Mensurando a criação de valor na gestão pública. Revista Administração Pública, Rio de Janeiro, v. 38, n. 3, p. 423-449, 2004.

CHIARINI, T. Análise espacial da pobreza municipal no Ceará, 1991-2000. Revista de Economia, v. 34, n. 2, p. 69-93, 2008.

CZERMAInskI, A. B. C. Análise de correspondência. São Paulo: USP/Escola Superior de Agricultura "Luiz de Queiroz", 2004.

DATT, G.; RAVALLION, M. Growth and redistribution components of changes in poverty measures: a decomposition with application to Brazil and India in the 1980s. Journal of Development Economics, v. 38, n. 2, p. 275-295, 1992.

FosU, A. K. Inequality and the impact of growth on poverty: comparative evidence for Sub-Saharan Africa. Journal of Development Studies, v. 45, n. 5, p. 726-745, 2009.

. Growth, inequality, and poverty reduction in developing countries: recent global evidence. Helsinki: World Institute for Development Economics Research, 2011 (Working Paper n. 2011-1).

. Growth, inequality, and poverty in Sub-Saharan Africa: recent progress in a global context. Oxford Development Studies, v. 43, n. 1, p. 44-59, 2015.

Hoffmann, R. Estatística para economistas. 4.ed. São Paulo: Pioneira Thomson Learning, 2006. $432 \mathrm{p}$.

HolANDA, M. C. et al. O modelo aplicado de gestão pública por resultados (GPR) no Estado do Ceará. In: HoLANDA, M.C. (Org.) Ceará: a prática de uma gestão pública por resultados. Fortaleza: Ipece, 2006, p. 55-76. 
HoLANDA, M. C. et al. Implementing results-based management at the subnational level. In: Ashbourne, E.; KUIL, I.; LEGER, D.; KOLKER, E. (Org.). Sourcebook on emerging good practices in Managing for Development Results. 3 ed. Washington, D.C.: World Bank, 2008, p. 59-63.

HolandA, M. C.; RosA, A. L. T. Fundo Estadual de Combate à Pobreza (Fecop). Fortaleza: Ipece, 2004a (Nota técnica n. 4).

. Gestão pública por resultados na perspectiva do Estado do Ceará. Fortaleza: Ipece, 2004b (Nota Técnica n. 11).

KAKWANI, N. Poverty and economic growth with application to Cote d'Ivoire. Review of Income and Wealth, v. 39, n. 2, p. 121-139, 1993.

KALWIJ, A.; VERSCHOOR, A. Not by growth alone: the role of the distribution of income in regional diversity in poverty reduction. European Economic Review, v. 51, p. 805-829, 2007.

KAPOOR, R. Inequality matters. In: Annual Global Development Conference Inequality, Social Protection and Inclusive Growth, 14. 2013, Manila. Anais... Manila: Global Development Network (GDN), 2013.

LOUREIRO, A. O. F.; COSTA, L. O. Uma breve discussão sobre os modelos com dados em painel. Fortaleza: Ipece, 2009 (Nota Técnica n. 37).

LOUREIRO, A. O. F.; SUlIANO, D. C. As principais linhas de pobreza utilizadas no Brasil. Fortaleza: Ipece, 2009 (Nota Técnica n. 38).

MACroplan. Levantamento de práticas de Gestão Pública para Resultados Benchmarking GpR. Fortaleza, mar. 2016. Disponível em: http://www.seplag. ce.gov.br/images/stories/Planejamento/Gestao-Publica-por-Resultado/2016\%20 \%20Projeto\%20GPR/Levantamento\%20de\%20pr\%C3\%A1ticas\%20de\%20 Gest\%C3\%A30\%20P\%C3\%BAblica\%20para\%20Resultados\%20\%E2\%80\%93\%20 Benchmarking\%20GpR.pdf Consulta em: 15 jul. 2016.

MARINHo, E.; ARAújo, J. Crescimento econômico e concentração de renda: seus efeitos na pobreza no Brasil. Rio de Janeiro / Niteroi: BNDES/Anpec, 2012 (Working Paper n. 24).

Medeiros, A. C. C. GPR no Ceará: prática de gestão em busca de resultados. In: Congresso Consad de Gestão Pública, 3. Brasília (DF), 2010. Anais... Brasília: Consad, 2010.

Medeiros, A. C. C.; RosA, A. L. T.; NogueirA, C. A. G. Gestão pública por resultados: uma análise comparativa entre os modelos do Ceará e do Canadá. Encontro Economia do Ceará em Debate, 4. Fortaleza (CE), 2008. Anais... Fortaleza: Ipece, 2008.

Medeiros, C. N.; Pinho Neto, V. R. Mapeamento da extrema pobreza no estado do Ceará. In: Barreto, F. A. D.; Menezes, A. S. B.; Albuquerque, E. L. S.; Sousa, F. J.; GonçALVES, L. C. (Orgs.). Economia do Ceará em Debate 2011. Fortaleza: Ipece, 2012. p. 167-190.

Neri, M. Bolsa Família 2.0. Conjuntura Econômica, Rio de Janeiro, v. 60, n. 12, p. 46-49, dez. 2006. 
NogueirA, C. A. G. Acompanhamento das metas do milênio e dos avanços socioeconômicos do Ceará. Fortaleza: Ipece, 2009 (Texto para Discussão n. 57).

NogueirA, C. A. G.; Pontes, P. A. Planejamento e gestão governamental na esfera estadual: uma análise comparativa dos processos, conteúdos e sistemas de acompanhamento dos PPAs - Estado do Ceará. Brasília: Ipea, 2013. (Relatório de Pesquisa).

Planejamento e gestão governamental na esfera estadual: a experiência do Ceará. In: CARdoso JR., J. C.; SANTOS, J. C.; PIRES, R. R. (Orgs.). PPA 2012 - 2015: a experiência subnacional de planejamento no Brasil. Brasília: Ipea, 2015, p. 123-151. OCDE. The productivity-inclusiveness nexus. Paris, 2016.

Oliveira, J. L.; miRo, V. H.; BARReto, F. A. F. D. Princípios para uma estratégia eficiente de combate à pobreza no estado do Ceará. Fortaleza: Ipece, 2013 (Nota Técnica n.53).

PEREIRA, A. Guia prático de utilização do SPSS - análise de dados para Ciências Sociais e Psicologia. 5.ed. Lisboa: Edições Sílabo, 2004. 243 p.

Pero, V.; Cruz, G. F. A queda da pobreza no Brasil: mudanças no perfil e nos determinantes na entrada do 20 milênio. In: Encontro Nacional de Economia, 43., 2015, Florianópolis. Anais... Florianópolis: ANPEC, 2015.

Pestana, M. H.; Gageiro, J. N. Análise de dados para ciências sociais - a complementaridade do SPSS. 6.ed. Lisboa: Edições Sílabo, 2014. 1240 p.

PNUD. Os objetivos de desenvolvimento sustentável - dos ODM para os ODS. Disponível em: http://www.undp.org/content/brazil/pt/home/post-2015/Consulta em: 05 jul. 2016.

PNUD; IPEA; FJP. Atlas do Desenvolvimento Humano no Brasil. 2013. Disponível em: http://www.atlasbrasil.org.br/2013/ Consulta em: 05 out. 2015.

RAMos, C. A. A queda da pobreza e da concentração de renda no Brasil. "À la Recherche" da teoria perdida. Nova Economia, Belo Horizonte, n. 25, v. 3, p. 599620, set./dez. 2015.

RAY, D. Development Economics. Princeton: Princeton University Press, 1998. 848 p. RochA, S. Pobreza no Brasil: afinal, de que se trata? 3.ed. Rio de Janeiro: Editora FGV, 2006. 244 p.

SACHS, J. The end of poverty: how we can make it happen in our lifetime. Nova York: Penguin Books, 2005. 397 p.

SEN, A. Desenvolvimento como liberdade. São Paulo: Companhia das Letras, 2000. $411 \mathrm{p}$.

THORBECKE, E. Multidimensional poverty: conceptual and measurement issues. In: KAKWANI, N.; SILBER, J. (Eds.) The many dimensions of poverty. Basingstoke: Palgrave Macmillan, 2007. p. 3-19.

ZAMAN, K.; KHILJI, B. A. The relationship between growth-inequality-poverty triangle and pro-poor growth policies in Pakistan: the twin disappointments. Economic Modelling, v. 30, p. 375-393, 2013. 


\section{Cláudio André Gondim Nogueira}

Doutor em Administração de Empresas pela Universidade de Fortaleza (Unifor). Atualmente é Diretor da Diretoria de Estudos de Gestão Pública (Digep) do Instituto de Pesquisa e Estratégia Econômica do Ceará (Ipece) e professor de cursos de pós-graduação latu sensu da Unifor. Contato: sergioforte@unifor.br

\section{Sérgio Henrique Arruda Cavalcante Forte}

Doutor em Administração de Empresas pela Fundação Getulio Vargas (FGV). Atualmente é professor titular da Universidade de Fortaleza (Unifor) no programa de Pós-Graduação em Administração (PPGA) e no Centro de Comunicação e Gestão (CCG). Contato: sergioforte@unifor.br 